\title{
Electrostatic complex of neurotrophin 4 with dendrimer nanoparticles: controlled release of protein in vitro and in vivo
}

This article was published in the following Dove Press journal: International Journal of Nanomedicine

\author{
Maria Dąbkowska' \\ Dorota Rogińska ${ }^{2}$ \\ Patrycja Kłos' \\ Anna Sobuś ${ }^{2}$ \\ Małgorzata Adamczak ${ }^{3}$ \\ Zofia Litwińska ${ }^{2}$ \\ Anna Machalińska ${ }^{4}$ \\ Bogusław Machaliński ${ }^{2}$ \\ 'Department of Medical Chemistry, \\ Pomeranian Medical University, Szczecin \\ 70-204, Poland; ${ }^{2}$ Department of General \\ Pathology, Pomeranian Medical \\ University, Szczecin 70-204, Poland; \\ ${ }^{3}$ Department of Pharmacy, School of \\ Pharmacy, University of Oslo, Blindern, \\ Oslo 0316, Norway; ${ }^{4}$ First Department \\ of Ophthalmology, Pomeranian Medical \\ University, Szczecin 70-204, Poland
}

Correspondence: Maria Dąbkowska Department of Medical Chemistry, Pomeranian Medical University, I Rybacka, Szczecin 70-204, Poland Email maria.dabkowska@pum.edu.pl

Bogusław Machaliński Department of General Pathology, Pomeranian Medical University, I Rybacka, Szczecin 70-204, Poland Email machalin@pum.edu.pl
Background: NT4 has been regarded as a promising therapeutic protein for treatment of damaged retinal pigment epithelium cells.

Purpose: Here, we studied physicochemical parameters of an NT4-polyamidoamine (PAMAM) electrostatic complex, which can provide a sustained concentration of protein in intraocular space over an extended period after delivery. Adsorption/desorption of NT4 molecules to/from positively charged PAMAM dendrimers were precisely determined to control the concentration of bounded/unbounded protein molecules, diffusion coefficient, and size of a protein-laden dendrimer structure. We determined kinetics of NT4 desorption in PBS, vitreous, and damaged retina.

Methods: Initially, adsorption of NT4 molecules on PAMAM dendrimers was studied in PBS using dynamic light scattering, electrophoresis, solution depletion, ELISA, and atomic force microscopy. This allowed us precisely to determine desorption of NT4 from nanoparticles under in situ conditions. The maximum coverage of irreversibly adsorbed NT4 determined by ELISA allowed us to devise a robust procedure for preparing stable and well-controlled coverage of NT4 on PAMAM nanoparticles. Thereafter, we studied diffusion of nanospheres containing NT4 molecules by injecting them into vitreous cavities of mice exposed to intravenous injections of sodium iodate and evaluated their intraocular desorption kinetics from drug carriers in vivo.

Results: Our measurements revealed NT4-dendrimer nanoparticles can be used for continuous neurotrophic factor delivery, enhancing its distribution into mouse vitreous, as well as damaged retina over 28 days of postinjury observation.

Conclusion: Understanding of polyvalent neurotrophin interactions with dendrimer nanoparticles might be useful to obtain well-ordered protein layers, targeting future development of drug-delivery systems, especially for neuroprotection of damaged retinal neurons.

Keywords: neurotrophin 4, NT4, retinal pigment epithelium, therapeutic protein, dendrimer functionalization, controlled release of protein, NT4-PAMAM electrostatic complex

\section{Introduction}

NT4 is a growth factor that belongs to a family of neurotrophic factors/neurotrophins that act via different classes of receptors, ${ }^{1,2}$ leading to the subsequent activation of various signaling pathways in target cells. Two classes of receptorhave been identified: p75, which is a member of the TNF-receptor family, and Trk, belonging to the integral tyrosine-kinase family. In our previous work ${ }^{3}$ we studied NT4-TrkB signaling in mesenchymal stem cells in retina and subsequent Akt- and MAPKrelated pathway activation. These pathways may modulate the development and 
maintenance of the vertebrate nervous system via promoting survival, migration, proliferation, differentiation, and death of neurons. ${ }^{4-6}$ Synthesis, secreted concentration, and half-life of NT4 in the human body are limited. NT4 is not available for all neurons; therefore, its delivery from cells to tissue results in concentration gradients. ${ }^{3}$ Decreased neurotrophin concentration has been associated with several neurodegenerative diseases and their symptoms. ${ }^{4,7}$ Accordingly, improved administration of exogenous NT4 and consequent neuroprotection has been considered a potentially novel treatment for neurodegenerative diseases, ${ }^{5,8,9}$ including retinal degeneration. The survivalpromoting activity of neuroprotective agents in diverse neuronal systems has been studied recently to determine their use in retinal disorders. Neurotrophins have been used for the rescue of photoreceptors from retinal damage, as described by La Vail et al, ${ }^{10}$ Paskowitz et al $^{11}$ and Birch et al. ${ }^{12}$

NT4 delivery can be achieved more easily in the eye than other organs, because the treated tissue surface is small inside the ocular globe, very little diffusion of proteinaceous compound is expected, due to ocular barriers, and thus proteins with molecular weight of $55 \mathrm{kDa}$ can easily reach the retina through diffusion from the vitreous. ${ }^{13}$ However, carrier-free administration of NT4 is relatively unstable, because of rapid degradation in biological media as a result of very short in vivo half-life and low bioavailability. On the other hand, biodistribution of nanosize carrier systems after intravitreous injection is highly influenced by the surface of nanoparticles. $^{14,15}$

Dendrimer is a monodisperse therapeutic scaffold that allows NT4 delivery to damaged retinal pigment ephitelium (RPE) cells, enhancing its local concentration and protein stability against enzymatic degradation. Moreover, distribution of well-controlled, multiple reactive surface groups that have great structural adaptability qualifies dendrimers to improve cargo of NT4 as a functional molecule. Physicochemical properties of this densely branched polyelectrolyte with well-defined spherical geometry enhances stability and surface functionality of the NT4-delivery system. With the use of dendrimer, NT4 can be effective only where it is needed. The size of polyamidoamine (PAMAM) dendrimer 6 generation enables its efficient diffusion efficiently across the vitreous body. It can be internalized into cells and removed rapidlyby the kidneys. ${ }^{16-18}$ Dendrimers present strong ability to escape uptake by the aspecific reticuloendothelial system and consequently remain for plenty of time in the blood circulation, increasing their biological potency in specific tissue sites in therapeutic approaches. ${ }^{19}$ Using dendrimers as a rapidly removable platform for delivery of protein helps to avoid long-term toxicity. ${ }^{20-23}$ In a localized manner, NT4-PAMAM nanoparticles can be administrated as an ocular drug to treat ophthalmic disease. Due to their high degree of structural control (monodispersity and tunable chemical structure), ${ }^{24-28}$ dendrimers are widely utilized in vivo as biological functional nanocarriers for drugs, ${ }^{29}$ biomacromolecules, gene delivery, ${ }^{30-32}$ imaging agents, ${ }^{33,34}$ and diagnostic products. $^{35}$ The polyvalent interaction of dendrimers with protein ${ }^{36}$ resembles a common type of interaction between biological entities, such as receptors and ligands or viruses and cell surfaces. ${ }^{37-39}$ Although NT4 can be a promising therapeutic agent, adsorption of this protein molecule at dendrimer-nanoparticle surfaces remains not fully elucidated.

Therefore, the present study was designed to elucidate the mechanism of NT4 adsorption/desorption at well-characterized PAMAM dendrimer nanoparticles and investigate diffusion of NT4-PAMAM after administration into eyes in real time up to 28 days. In this paper, we formulate reliable clues as to the adsorption/desorption mechanism of NT4 to/ from PAMAM nanoparticles, which is generally governed by electrostatic interactions between the protein and polymer surface, van der Waals forces, and structural adaptation of the protein. The main goal of our study was to determine the physicochemical parameters of PAMAM, NT4, and NT4-PAMAM drug-delivery system to assess the usefulness of NT4-PAMAM in an in vitro model. This NT4 PAMAM electrostatic complex allows controlled release of NT4; therefore, different complementary techniques were performed to confirm adsorption/desorption of NT4 protein to/from the PAMAM surface. ELISA measurements were performed to monitor the progress of protein desorption in situ in PBS, as well as in vitro in vitreous humour, retinas, and whole mouse eyes. The reversibility of adsorbed/desorbed protein was determined precisely via laser Doppler velocimetry (LDV) and atomic force microscopy (AFM) measurements and compared with the ELISA results, thus providing reliable data for bulk NT4 concentration as low as $0.1 \mathrm{mg} \cdot \mathrm{L}^{-1}$. In this way, one can unequivocally prove the irreversibility of NT4 adsorption for a low-concentration protein range. It should be mentioned that this method has been efficiently used before to determine adsorption mechanisms of lysozymes, ${ }^{40}$ human serum albumin, ${ }^{41}$ and fibrinogen $^{42}$ on polystyrene microparticles. 
Our previous studies suggested that NT4 particularly promotes survival and neuroprotection of retinal neurons during the course of acute chemical damage to the murine retina. ${ }^{3}$ As such, here we studied NT4 as a low-molecularweight therapeutic agent in an ocular drug-delivery system. Sustained controlled release of NT4 for 14 days and up to 28 days from the proposed PAMAM drug-delivery system could promote damaged RPE regeneration and functional recovery. Understanding the adsorption/desorption process of NT4 to/from PAMAM dendrimers could constrain the use of polyelectrolytes or surfactantmediated systems for eye application.

\section{Methods}

\section{NT4, PAMAM, and NT4-PAMAM conjugates}

Filtered (Centrifree ultrafiltration device; Merck, Darmstadt, Germany) stock solutions of carrier-free recombinant human NT4 (268-N4-025/CF; R\&D Systems) of known concentrations (typically $250 \mathrm{mg} \cdot \mathrm{L}^{-1}$ ) in PBS (pH 7.4 \pm 0.2 ; Biomed, Lublin, Poland) were prepared to remove aggregates and provide a constant, free-form protein-molecule concentration in the solvent. To minimize errors in concentration measurements, two complementary spectrophotometric techniques were used: a BCA protein-quantification kit for low concentration (Abcam), and ultraviolet absorbance at $280 \mathrm{~nm}$ measured with microplate spectrophotometry (BioTek Epoch). Prior to each measurement, the stock solution was diluted to a desired bulk concentration, typically $10-50 \mathrm{mg} \cdot \mathrm{L}^{-1}$. The exact concentration of these solutions after membrane filtration was determined by commercially available ELISA kits (DY992, DY990, DY994, DY999, DY995, WA126, DY006, and DY268; R\&D Systems). The temperature of experiments was kept at a constant $298 \pm 0.1 \mathrm{~K}$.

A suspension of PAMAM G6 ethylenediamine-core sixth-generation dendrimers, (536717; Sigma-Aldrich, St Louis, MO, USA) was used as a colloid carrier for NT4. The stock suspension of well-defined concentration was purified by dialysis using a Slide-A-Lyzer dialysis cassette (Thermo Fisher Scientific, Waltham, MA, USA) to remove low-molecular-weight impurities. Using ultraviolet-visible spectrophotometry, we determined the exact concentration of G6 PAMAM dendrimers after purification using the ninhydrin assay. ${ }^{43}$ This procedure is based on the interaction of the primary amino group of PAMAM dendrimers with ninhydrin (Sigma-Aldrich) to form a blue product. According to this protocol, we were able to determine the concentration of dendrimer molecules in the range of $25-200 \mathrm{mg} / \mathrm{ml}$. Afterward, the stock suspension was diluted prior to each adsorption experiment to a desired mass concentration of 50 $\mathrm{mg} \cdot \mathrm{L}^{-1}$ and filtered to remove aggregates with the lowest binding membrane for protein solutions $(0.1 \mu \mathrm{m}$, VDF Durapore; Merck Millipore).

NT4 adsorption at PAMAM dendrimers was performed: the reference electrophoretic mobility of bare PAMAM nanoparticles was measured, NT4 monolayers were formed by mixing equal volumes of solutions of bulk concentration $\left(0-40 \mathrm{mg} \cdot \mathrm{L}^{-1}\right)$ with nanoparticle suspensions of bulk concentrations of $100 \mathrm{mg} \cdot \mathrm{L}^{-1}$, and the electrophoretic mobility of NT4-PAMAM nanoparticles was measured and the corresponding $\zeta$-potential calculated. Final experiments were performed at $\mathrm{pH} 7.4$, ionic strength $0.15 \mathrm{M}$, temperature $20^{\circ} \mathrm{C}$. This procedure enables direct in situ determination of hydrodynamic size, electrophoretic mobility and $\zeta$-potential variations as a function of bulk concentration of NT4. The adsorption time of NT4 at PAMAM dendrimers was 1,800 seconds in the primary adsorption experiments. The relaxation time of the lysozyme (similar molecular mass to NT4 molecule) monolayer on microparticles was around 2 seconds fora full monolayer. ${ }^{40,44}$ The time for formation of additional layers is much longer than monolayer formation. In all cases, NT4 should be irreversibly adsorbed onto the surface as a result of short-range electrostatic interactions between NT4 and PAMAM, since the adsorption process is mediated by electrostatic interactions.

The diffusion coefficient of NT4, PAMAM, and the NT4-PAMAM conjugate was determined by dynamic light scattering (DLS; Malvern Zetasizer Nano ZS). The electrophoretic mobility of NT4 molecules, bare PAMAM, and NT4-PAMAM conjugate was measured with LDV with the aid of the aforementioned Malvern device. Suspensions of nanoparticles and protein diluted in PBS to a suitable concentration were used for these analyses. Data analysis was performed in automatic mode at $25^{\circ} \mathrm{C}$. Measured size was presented as the average value of 20 runs, with triplicate measurements within each run.

\section{NT4 surface concentration}

Ruby muscovite mica (Continental Trade, Poland) was used as a substrate for NT4, PAMAM, and NT4-PAMAM adsorption measurements. Fresh solid pieces of mica were cleaved into thin sheets prior to every experiment. AFM was used to obtain information about the binding strength 
of NT4 on PAMAM dendrimers. In parallel with ELISA measurements, the unbound (residual) NT4 surface concentration after adsorption was determined directly by AFM imaging. In the former case, the nanoparticle-NT4 mixture and supernatant acquired after the adsorption step were left to deposit on mica sheets placed in the diffusion cell over a controlled time, and then the substrate was removed and rinsed for half an hour in ultrapure water. Samples were left for air-drying until the next day. AFM measurements were carried out under ambient air conditions using a NanoWizard (JPK Instruments). Intermittent contact-mode images were obtained in the air using ultrasharp silicon cantilevers (NSC35/AlBS; MicroMash), and the cone angle of the tip was $<20^{\circ}$. Images were recorded at a scan rate of $1 \mathrm{~Hz}$ for the six randomly chosen places. Images were flattened using an algorithm provided with the instrument. We captured all images in random areas within a scan size of $0.5 \times 0.5 \mu \mathrm{m}$ or $1 \times 1 \mu \mathrm{m}$. NT4 surface dimension and concentration were determined using ImageJ software by gathering the number and coordinates of single protein molecules. Manual counting of NT4 molecules was based on comparing the original image and the same picture altered by digital image filters by cutting off the picture background. Once the number of protein molecules had been established, the residual bulk concentration of NT4 and consequently its coverage on PAMAM nanoparticles was calculated.

\section{Quantification of NT4}

Adsorption/desorption of NT4 molecules at/from nanoparticles was studied with ELISA according to the manufacturer's protocol. Initially, the residual (unbound) NT4 concentration in the filtrate was determined by applying a sandwich ELISA technique to monitor simultaneously the maximum concentration of NT4 in the supernatant suspensions, acquired after adsorption at PAMAM nanoparticles. Standard and supernatant samples containing NT4 after ultrafiltration of PAMAM suspensions were added to the 96-well microplate precoated. Therefore, it was possible precisely to determine the concentration of unadsorbed NT4 molecules at PAMAM nanoparticle surfaces separated by ultrafiltration.

\section{NT4-PAMAM-AF488 conjugates}

For detection of NT4-PAMAM conjugates on mouse-eye slides by confocal microscopy, a detectable fluorescent molecule, eg, PAMAM-AF488 was needed. We used AF488-NHS ester as fluorescent label. PAMAM at 2.5 $\mathrm{mg} \cdot \mathrm{ml}^{-1}$ in $\mathrm{pH} 8$ sodium bicarbonate buffer reacted with $1 \mathrm{mg} \cdot \mathrm{ml}^{-1}$ amine-reactive dye dissolved in dimethylformamide as described in the manufacturer's protocol to obtain fluorescently labeled PAMAM-AF488 conjugates. These conjugates were purified by extensive dialysis against $\mathrm{pH} 7.4$ to remove unreacted labeling. After dialysis, we further purified conjugates through centrifugal filtration until filtrate absorbance at $490 \mathrm{~nm}$ had reached background levels. Protein concentrations were determined using a total-protein assay (Micro BCA; Pierce). Afterward, NT4 adsorption at PAMAM-AF488 molecules was performed according to the procedure described in the "NT4, PAMAM, and NT4-PAMAM conjugates" section.

\section{Animals and experimental procedures}

Pathogen-free 12-week-old mature female BALB/c mice (Center for Experimental Medicine, Medical University of Bialystok, Poland) weighing $25 \pm 2 \mathrm{~g}$ were used in the experiment. Animals were maintained under standard conditions with a 12-hour day (160 lux)-night cycle and ad libitum feeding. All animal procedures were performed according to the regulations in the Association for Research in Vision and Ophthalmology Statement for the Use of Animals in Ophthalmic and Vision Research and were approved by the local ethics committee for experiments on animals in Poznań, Poland (approval 27/2017).

To study the penetration of encapsulated NT4 protein in vivo after intravitreal injection of PAMAM-NT4, we monitored vitreal and retinal levels of NT4 over 28 days. Prior to NT4 administration, mice were anesthetized $(\mathrm{n}=40)$, and sodium iodate $\left(\mathrm{NaIO}_{3}\right.$; Sigma-Aldrich $)$ in PBS at a dose of $30 \mathrm{mg} / \mathrm{kg}$ body weight was injected intravenously into the retroorbital sinus. Sodium iodate treatment is a well-characterized chemical model of acute retinal injury to study adjuvant or stem cell-based ocular therapy. ${ }^{3,45,46}$ Subsequently, 24 hours after the retinal lesions were induced, $1 \mu \mathrm{L}$ NT4 $(20 \mu \mathrm{g} / \mathrm{mL})$-PAMAM $(50 \mu \mathrm{g} / \mathrm{mL})$ or PAMAM $(50 \mu \mathrm{g} / \mathrm{mL})$ alone (both solutions prepared in PBS) were injected into the vitreal cavity using a $32 \mathrm{G}$ needle (Hamilton, Reno, NV, USA) to the left and right eyes, respectively ( $\mathrm{n}=20$ mice). Moreover, to track nanoparticles within the eye by confocal microscopy, some animals $(n=10)$ were intravitreally injected with 1 $\mu$ L NT4-PAMAM conjugated with AF88. Tissue samples were then collected on days 7 and 28 days after $\mathrm{NaIO}_{3}$ and nanoparticle administration. Animals with no treatment $(n=5)$ served as a control. 


\section{Tissue collection}

Mice were euthanized by cervical dislocation at selected time points: before and on days 7, 14, and 28 after $\mathrm{NaIO}_{3}$ alone, $\mathrm{NaIO}_{3}-\mathrm{PAMAM}, \mathrm{NaIO}_{3} / \mathrm{NT} 4-\mathrm{PAMAM}$, or $\mathrm{NaIO}_{3}-\mathrm{NT} 4$ PAMAM-AF488 administration $\quad(\mathrm{n}=10 \quad$ eyes/group/time point). Eyes were enucleated and subjected into different analyses. To study tissue levels of NT4 protein, corneas and lenses were removed from eyeballs by cutting along orae serratae with small scissors. Then, the vitreous was dissected and the remaining retina/RPE and vitreous were used separately to extract total protein for subsequent ELISA testing. For fluorescence imaging, enucleated eyes were fixed for 24 hours in Davidson's fixative, dehydrated by immersion in alcohol solutions of increasing concentrations $(50 \%, 70 \%, 80 \%, 96 \%$, and $100 \%$ ) for 5 minutes each and embedded in paraffin.

\section{Protein extraction}

To obtain total naïve protein, tissue samples were homogenized in $350 \mu \mathrm{L}$ ice-cold cell-disruption buffer (mirVana PARIS kit; Thermo Fisher Scientific), supplemented with a Phosphatase Inhibitor Cocktail Set II (Merck). After centrifugation, the supernatant was collected and stored at $-80^{\circ} \mathrm{C}$ until needed. The calculated concentration of NT4 protein on ELISA was normalized to the total protein concentration of the individual samples measured by Bradford assay (Sigma-Aldrich).

\section{Confocal imaging}

Paraffin blocks were cut into $5 \mu \mathrm{m}$-thick sections and mounted on microscopic slides for subsequent experiments. After 2-hour incubation in $58^{\circ} \mathrm{C}$, paraffin sections were subjected to deparaffinization in xylene, using two changes of 15 minutes each. Sections were then gradually hydrated through graded alcohols $100 \%, 96 \%, 80 \%, 70 \%$, and $50 \%, 5$ minutes in each - and subsequently washed in deionized $\mathrm{H}_{2} \mathrm{O}$ and PBS $\mathrm{pH} 7.4$, for 2 and 10 minutes, respectively. Next, nuclei were stained with DAPI (Thermo Fisher Scientific), for 5 minutes at room temperature in the dark, and specimens were washed three times in PBS. Tissue sections were mounted with Vectashield mounting medium (Vector Laboratories, Burlingame, CA, USA) and coverslipped. Confocal imaging was performed by means of laser-scanning confocal microscopy (AxioImager Z2; Carl Zeiss, Oberkochen, Germany) in $63 \times$ oil-immersion objective with excitation/emission wavelengths of $\lambda_{\mathrm{ex}}=490 \mathrm{~nm} / \lambda_{\mathrm{em}}=525 \mathrm{~nm}$ for AF488 and $\lambda_{\mathrm{ex}}=358 \mathrm{~nm} /$ $\lambda_{\mathrm{em}}=461 \mathrm{~nm}$ for DAPI.

\section{Statistical analysis}

Statistical analysis within each study group was performed using the Kruskal-Wallis test. Two-way ANOVA was used for analysis between experimental groups. $P<0.05$ was considered statistically significant. Data are presented as mean $\pm \mathrm{SD}$.

\section{Results and discussion NT4 and PAMAM physicochemical characteristics}

It was determined by DLS that for a PBS concentration of $0.15 \mathrm{M}$ at $\mathrm{pH} 7.4$, diffusion coefficients of NT4 and PAMAM molecules were $10.8 \times 10^{-7} \pm 0.1 \mathrm{~cm}^{2} \cdot \mathrm{s}^{-1}$ and $6.3 \times 10^{-6} \pm 0.1 \mathrm{~cm}^{2} \cdot \mathrm{s}^{-1}$ (at $298 \mathrm{~K}$ ), respectively, which is in agreement with our previous results. ${ }^{47}$ Based on the known diffusion coefficient, the hydrodynamic diameters of NT4 and PAMAM were calculated using the StokesEinstein relationship:

$$
d_{H}=\frac{k T}{3 \pi \eta D}
$$

where $d_{H}$ is the hydrodynamic diameter, $k$ Boltzmann constant, $T$ absolute temperature, $\eta$ dynamic viscosity of water, and $D$ diffusion coefficient of protein or nanoparticles. The hydrodynamic diameter obtained for NT4 was $4.0 \pm 0.5 \mathrm{~nm}$ and for PAMAM $7.6 \pm 0.1 \mathrm{~nm}$. This corresponded to an NT4 molecule cross-section area of 14.2 $\mathrm{nm}^{2}$. Therefore, the "hydrodynamic" size of NT4 can be treated as a good estimate of its geometric size, given the structural stability of the protein and its compact shape.

In parallel, AFM was used to determine the geometric size of NT4 and PAMAM adsorbed under diffusion-controlled transport conditions on mica surfaces at $\mathrm{pH} 7.4$ and ionic strength $0.15 \mathrm{M}$ PBS. The average NT4 molecule occupied an equivalent sphere area, with diameter of $4.5 \pm 1.5 \mathrm{~nm}$, which was in good agreement with DLS bulk measurements. This is demonstrated in Figure 1A, where the presence of a larger number of NT4 oligomers at the mica surface in $\mathrm{pH} 7.4$ and ionic strength $0.15 \mathrm{M}$ PBS was not observed after ultrafiltration. As can be seen in Figure 1B, the average PAMAM molecule occupied an equivalent sphere area, with diameter of $3.5 \pm 1.5 \mathrm{~nm}$. According to these results, the size measured by AFM was in agreement with DLS bulk measurements, which are presented in Figure 1.

Figure 1B depicts monodisperse distribution of dendrimer size, where $85 \%$ of adsorbed PAMAM molecules at the mica surface had similar diameter. Figure 1B and DLS 

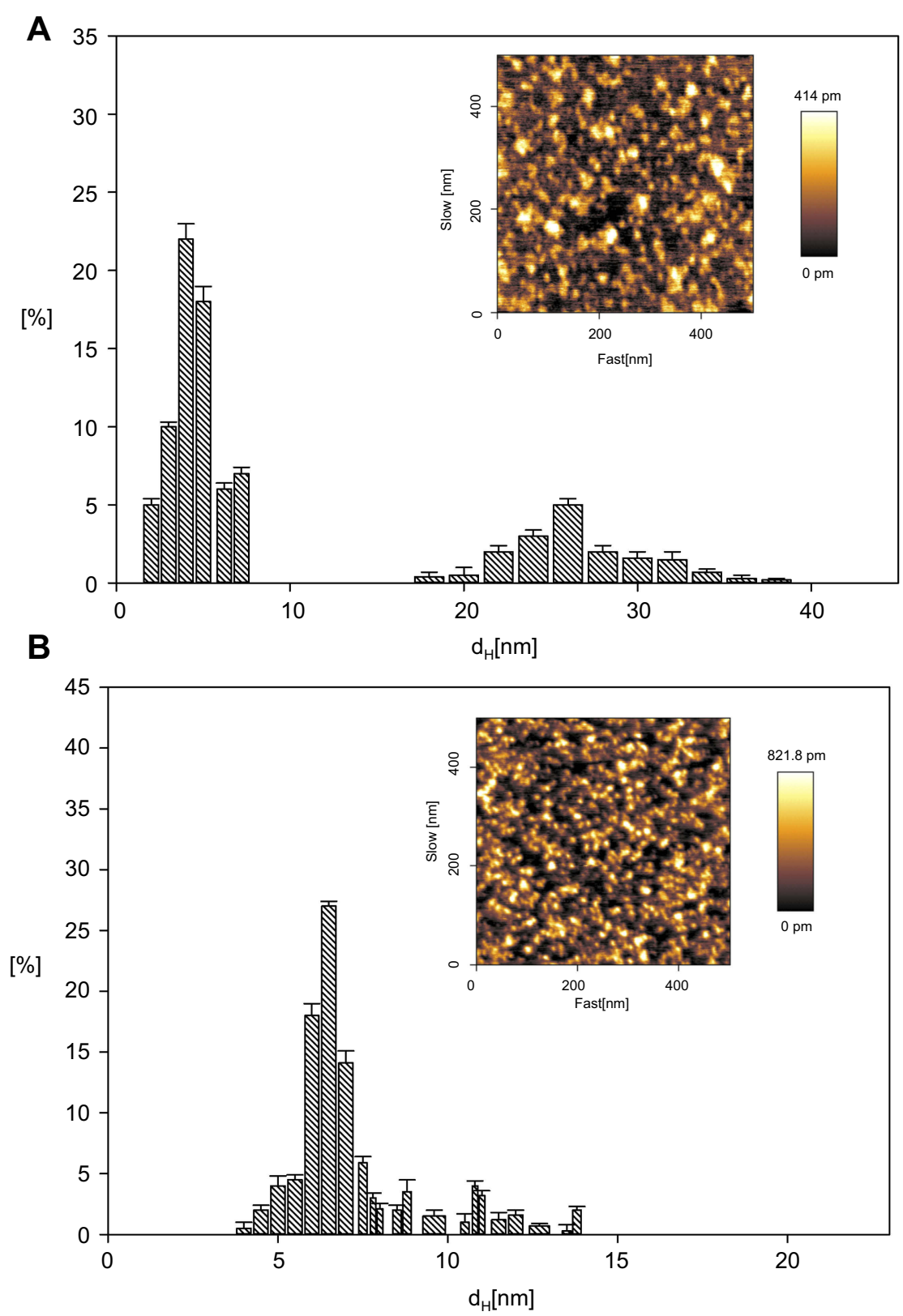

Figure I Histogram of adsorbed (A) NT4 and (B) PAMAM nanoparticles (PBS, 0.15 M, pH 7.4) indicated by direct AFM enumeration obtained for low surface-molecule concentration.

Notes: Figure created by taking into account ten randomly chosen areas, where each micrograph of the NT4 or PAMAM monolayer at the mica surface has a size of $0.5 \times 05$ $\mu \mathrm{m}$. Insets show the NT4 monolayer (A) and PAMAM monolayer (B) on mica, for surface concentration of individual molecules of approximately $800 / \mu m^{2}$.

Abbreviations: PAMAM, polyamidoamine; AFM, atomic force microscopy.

measurements (polydispersity index $=1.03$, in good accordance with Mullen et $\mathrm{al}^{48}$ ) proved that it was more likely for NT4 oligomers to appear at a solid surface than for PAMAM (Figure 1A). We observed some adsorbed NT4 aggregates with diameters $11.4 \pm 2 \mathrm{~nm}$ and $22.4 \pm 4 \mathrm{~nm}$ at the mica surface.

To understand the release mechanism from encapsulation-free NT4-PAMAM electrostatic complexes, we determined the distribution of positive and negative charges on nanoparticles and protein surfaces, which is a prerequisite for occurrence of attractive electrostatic interaction between them. The electrophoretic mobility $\left(\mu_{e}\right)$ of NT4 and PAMAM molecules was measured for $0.15 \mathrm{M}$ PBS concentrations at $\mathrm{pH} 7.4$ using the LDV method and was 1.16 and $-0.47 \mu \mathrm{m} \cdot \mathrm{cm}(\mathrm{Vs})^{-1}$, respectively. These values corresponded to $\zeta$-potentials of $22.2 \mathrm{mV}$ and $-8.2 \mathrm{mV}$, respectively, calculated using the Henry model. Knowing the electrophoretic 
mobility, it was possible to calculate the electrokinetic charge per NT4 molecule, $Q_{\mathrm{c}}$, from the Lorenz-Stokes relationship: ${ }^{49-51}$

$$
Q_{c}=3 \pi d_{H} \mu_{e}
$$

which is expressed in Coulombs, with $\eta$ the dynamic viscosity of the solvent (water), $d_{H}$ expressed in $\mathrm{nm}$, and $\mu_{e}$ expressed in $\mu \mathrm{m} \cdot \mathrm{cm} / \mathrm{V}$ s.

Equation 2 is valid for molecules of arbitrary shape and absolute $\zeta$-potential value $<50 \mathrm{mV}$, though has some limitations for higher ionic strengths, where double-layer thickness becomes less than the protein dimension. Therefore, while calculating the electrokinetic charge $Q_{c}$ for ionic strength of $0.15 \mathrm{M}$, we applied a previously used equation: ${ }^{37,52,53}$

$$
\mathcal{Q}_{c}=2 \pi \eta d_{H} \frac{1+\kappa d_{H}}{f_{H}\left(\kappa d_{H}\right)} \mu_{e}=2 \pi \eta d_{H}\left(1+\kappa d_{H}\right)
$$

The effective charge of PAMAM was a useful bulk characteristic for interpretation of electrostatic adsorption and desorption of NT4 molecules from these nanospheres. This approach does not require a chemical reaction, ie, is used routinely as an electron-dense marker. ${ }^{54-56}$ As discussed in Mullen et $\mathrm{al}^{48}{ }^{48}$ dendrimers have a uniform surface-charge density. This can be obtained from electrophoretic mobility and the hydrodynamic diameter of a nanoparticle, and one can calculate the average number of charges per molecule from the Lorentz-Stokes relationship. The results of this calculation are collected in Table 1, according to Equations 1 and 2 at $\mathrm{pH}$ 7.4. NT4 molecules acquired a slightly negative net charge, whereas the charge of PAMAM nanoparticles was positive.

\section{Reservoir-based NT4-delivery system Adsorption of NT4 on PAMAM dendrimers in PBS}

Electrokinetic studies offer a distinct possibility of direct in situ determination of electric properties of proteins and dendrimers, and can be conveniently interpreted by lateral electrostatic interactions between adsorbed molecules. In accordance with this approach, the bulk transport of proteins is described by the phenomenological continuity equation. ${ }^{57}$ Selecting a system of well-established physicochemical properties allowed us to combine dynamic aspects of interfacial interactions between NT4 and the PAMAM surface. Experimental data for the hydrodynamic diameter of the protein-dendrimer delivery system obtained with DLS after adsorption of NT4 $\left(20 \mathrm{mg} \cdot \mathrm{L}^{-1}\right)$ at PAMAM $\left(50 \mathrm{mg} \cdot \mathrm{L}^{-1}\right)$ nanoparticles showed a mean diameter of $13.5 \pm 5 \mathrm{~nm}$ for the electrostatic complex.

Additionally, we determined the geometric size of NT4-PAMAM conjugates adsorbed on mica surfaces at pH 7.4, 0.15 M PBS using AFM (Figure 2). Considering that NT4 has a molecular weight of $14 \mathrm{kDa}$ and is $5 \mathrm{~nm}$ in length, the hydrodynamic diameter of a single PAMAM 6.0 molecule of molecular weight $58 \mathrm{kDa}$ was $7.8 \mathrm{~nm}$. As can be seen in Figure 2, the diameter of NT4-PAMAM conjugates was $18 \pm 5 \mathrm{~nm}$ after ultrafiltration.

The electrophoretic mobility of NT4-PAMAM conjugates was studied by the microelectrophoretic method using the Henry equation to calculate $\zeta$-potential, as described elsewhere. ${ }^{40-42}$ Data obtained in the primary adsorption experiments for $0.15 \mathrm{M} \mathrm{NaCl}$, pH 7.4 PBS are shown in Table 1 . The $\zeta$-potential of the NT4 $\left(20 \mathrm{mg} \cdot \mathrm{L}^{-1}\right)$-PAMAM $\left(50 \mathrm{mg} \cdot \mathrm{L}^{-1}\right)$ conjugate was $12 \pm 8 \mathrm{mV}$ for $\mathrm{pH} 7.4$ and $0.15 \mathrm{M}$ PBS. As expected, adsorption of protein with slightly negative charge led to a reduction in the surface charge of nanoparticles, which gained less positive charge. We also determined the dependence of the $\zeta$-potential of microparticles on the initial concentration of NT4 in the PAMAM suspension (after mixing), denoted by $c_{b}$ (Figure 3). The $\zeta$-potential abruptly decreased with NT4 concentration and approached $c_{b}>0.5 \mathrm{mg} \cdot \mathrm{L}^{-1}$ at plateau values of $-5 \mathrm{mV}$, for pH 7.4 0.15 M PBS.

Adsorption of the NT4-molecule monolayer on PAMAM nanoparticles was connected with significant changes in their apparent $\zeta$-potential, which can be efficiently monitored by LDV method, studied multiple times before for fibrinogen, recombinanthuman serum albumin, plasmid protein, and albu-

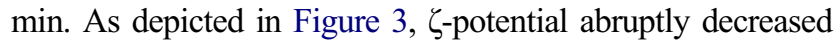
with increasing NT4 concentration and approached plateau

\begin{tabular}{|c|c|c|c|c|c|c|c|}
\hline \multirow[t]{2}{*}{ PBS concentration (M) } & \multicolumn{3}{|l|}{ PAMAM (G6) } & \multicolumn{4}{|l|}{ NT4 } \\
\hline & $\mu_{\mathrm{e}}\left(\mu \mathrm{m} \cdot \mathrm{cm}[\mathrm{Vs}]^{-1}\right)$ & $\zeta_{I}(\mathrm{mV})$ & $Q_{c}^{*}(e)$ & $\mu_{\mathrm{e}}\left(\mu \mathrm{m} \cdot \mathrm{cm}[\mathrm{Vs}]^{-1}\right)$ & $\zeta_{p}(\mathrm{mV})$ & $Q_{c}^{*}(e)$ & $\mathrm{Q}_{c}{ }^{* *}(\mathrm{e})$ \\
\hline $0.15, \mathrm{pH} 7.4$ & 1.16 & 22.2 & 5.8 & -0.47 & -8.2 & -1.0 & -1.7 \\
\hline
\end{tabular}

Table I Electrophoretic mobility, $\zeta$-potential, and charge density of PAMAM nanoparticles and NT4 molecules

Notes: *Calculated from Lorenz model; **calculated from $2 \pi d_{H} \frac{1+\kappa d_{H}}{f\left(\kappa d_{H}\right)} \mu_{e}$ (Henry model).

Abbreviation: PAMAM, polyamidoamine. 


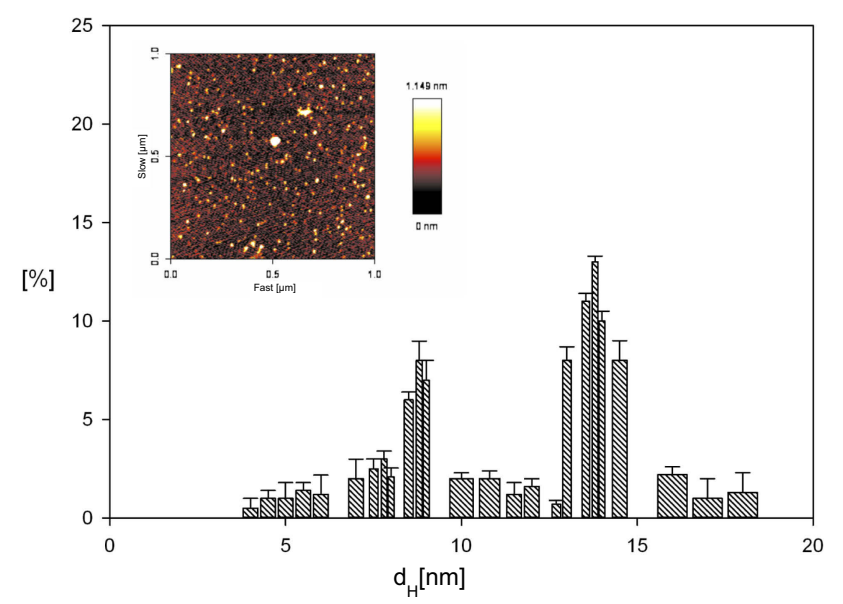

Figure 2 Adsorbed NT4-PAMAM (PBS, 0.15 M, pH 7.4) indicated by direct AFM enumeration obtained for low surface-molecule concentration.

Note: Figure created by taking into account ten randomly chosen areas, where each micrograph of the NT4-PAMAM monolayer at the mica surface has a size of $|\times| \mu \mathrm{m}$. Abbreviations: PAMAM, polyamidoamine; AFM, atomic force microscopy.

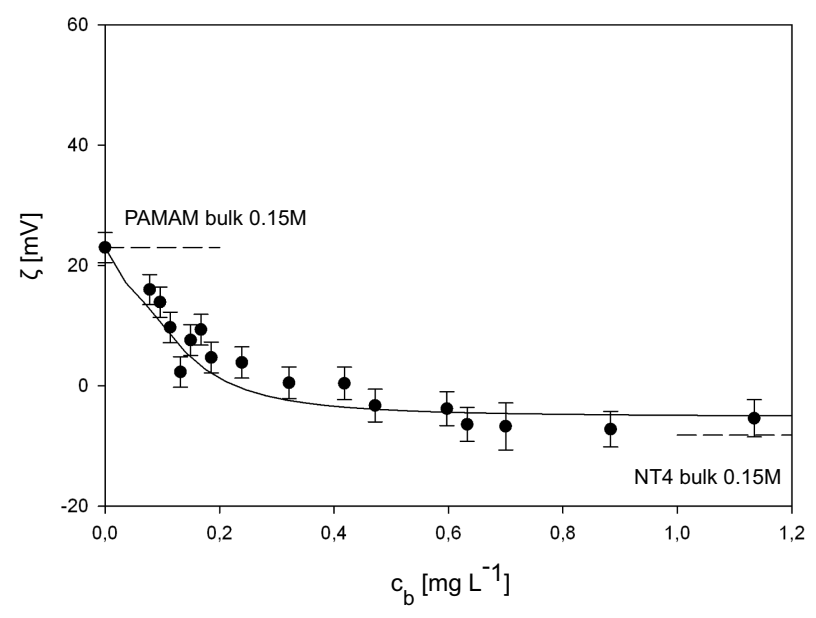

Figure 3 Dependence of $\zeta$-potential of PAMAM nanoparticles on bulk concentration of NT4 in the suspension after mixing $c_{b}$.

Notes: Points show experimental results obtained by laser Doppler velocimetry

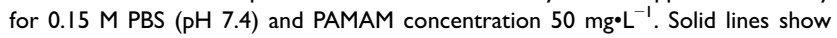
linear fit of data. Dashed lines show $\zeta$-potential of bare microparticles. Abbreviation: PAMAM, polyamidoamine.

values of $-5.8 \mathrm{mV}$, which was slightly below the $\zeta$-potential of NT4 in the bulk ( $-8.2 \mathrm{mV}$ at $0.15 \mathrm{M}$ ionic strength). The electrophoretic mobility of the NT4-PAMAM complex was 0.7 the electrophoretic mobility of bulk protein, which corresponded to the formation of an NT monolayer on PAMAM from $0.5 \mathrm{mgL}^{-1} \mathrm{NT} 4$ concentration. The use of higher NT4 concentration and prolonged adsorption up to 24 hours possibly resulted in multilayer formation (Figure 4). Moreover, in additional experiments, we confirmed that NT4 adsorption at the first layer/monolayer was irreversible. We did not observe changes in electrophoretic mobility ( $\zeta$-potential) over time up to 360 hours, which suggests that the $\zeta$-potential of PAMAM after NT4 adsorption (for NT4 bulk concentration up to 0.6 $\mathrm{mgL}^{-1}$; Figure 3) was only dependent only on NT coverage. Based on the data shown in Figure 3, we concluded that the densely packed monolayer of NT4 on nanoparticles started from $0.6 \mathrm{mg} \cdot \mathrm{L}^{-1}$. NT4 adsorption onto PAMAM nanoparticles was found to be in agreement with previous results observed by Serra et $\mathrm{al}^{58}$ for polyclonal $\mathrm{IgG}$, Bratek-Skicki et $\mathrm{al}^{42}$ for human serum fibrinogen, and Dąbkowska et $\mathrm{al}^{40}$ for lysozymes, where results were interpreted in terms of the electrokinetic model previously applied in simple and reliable LDV measurements. LDV measurement of the electrophoretic mobility of microparticles enables determination of the bulk concentration of protein, even for a range of $0.1-1 \mathrm{mg} \cdot \mathrm{L}^{-1}$, ie, the nanomolar concentration range, ${ }^{41}$ thus indicating that electrostatic interactions have a pivotal role in adsorption process, which we have already observed for lysozymes, another protein with low molecular weight, just as with NT4.

Our results are in accordance with maximum coverage of similar molecular weight to NT4 protein, and can be found in our recent work. ${ }^{40}$ Similar data were also obtained for protein-molecule adsorption at silica particles (20 $\mathrm{nm}$ in diameter), ${ }^{59}$ colloidal alumina particles $(180 \mathrm{~nm})^{60}$ and soda lime glass $(74.5 \mathrm{~nm}) .{ }^{61}$ However, in other work, much larger values for maximum protein coverage were reported, which can most probably be attributed to adsorption of aggregates.

The small slope seen on the chart in Figure 3 means that estimation of maximum protein coverage directly from electrophoretic mobility measurements was less accurate for concentration $>0.8 \mathrm{mg} \bullet \mathrm{L}^{-1}$ at higher ionic strength, eg, $0.15 \mathrm{M}$ PBS. Therefore, we used ELISA to determine residual (free) NT4 concentration after adsorption at PAMAM nanoparticles (Figure 4).

As can be observed, for low initial NT4 concentration (1 $\mathrm{mg} \cdot \mathrm{L}^{-1}$ ) unbounded protein molecules in PBS were negligible, indicating that adsorption onto $50 \mathrm{mg} \cdot \mathrm{L}^{-1}$ PAMAM nanoparticles was almost complete. In this way, we conclude that NT4 molecules after adsorption at PAMAM ( $\mathrm{pH} 7.4$ in 0.15 M PBS) are likely to form a monolayer of single molecules or a multilayer of aggregated molecules, which correlates with adsorption time and protein concentration. Moreover, it can be noticed that at $\mathrm{pH} \mathrm{7.4,} \mathrm{close} \mathrm{to} \mathrm{the} \mathrm{isoelectric} \mathrm{point} \mathrm{of} \mathrm{NT4,}$ double-layer forces were weak, due to lowering protein net charge (Table 1). Under these conditions, double-layer forces were remarkably weak, and thus interactions between NT4 molecules increased compared to the same 


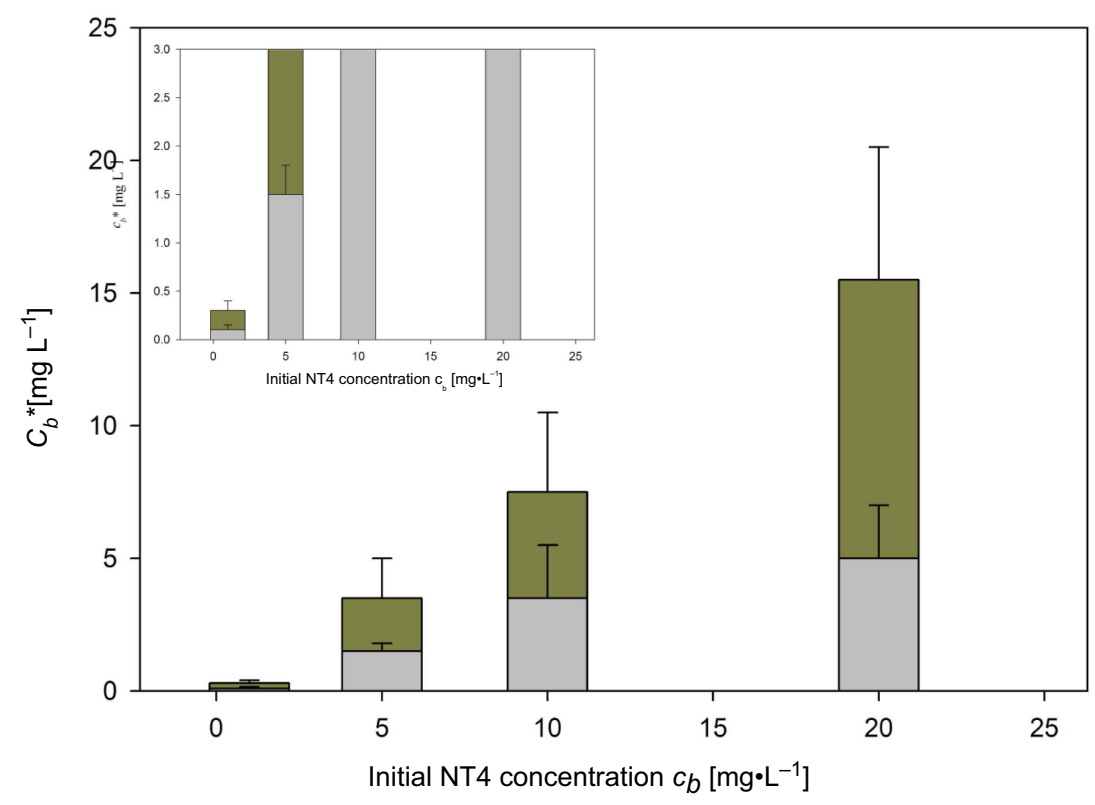

Figure 4 Dependence of residual NT4 concentration after adsorption step $c^{*}$ at PAMAM nanoparticles on initial protein concentration. Notes: Determined by ELISA at pH 7.4 in 0.15 M PBS after 24 hours' adsorption. Bars show data for bounded NT4 (gray) and residual NT4 (green). Abbreviation: PAMAM, polyamidoamine.

electrostatic interaction at lower $\mathrm{pH}$. Because of that, protein aggregation occurred, ie, aggregates consisting of two or three NT4 molecules assembled on the dendrimer surface. ${ }^{47}$ The large number of NT4 aggregates in the bulk formed due to the decrease in the range of lateral electrostatic interactions (double-layer thickness of $0.79 \mathrm{~nm}$ ) among adsorbed NT4 molecules at $0.15 \mathrm{M}$ ionic strength. The concentration of unbounded protein molecules increased systematically with increasing initial protein concentration from $1 \mathrm{mg} \cdot \mathrm{L}^{-1}$ to $20 \mathrm{mg} \cdot \mathrm{L}^{-1}$ (Figure 4), which clearly indicated the formation of NT4 aggregates on the dendrimer surface.

More importantly, maximum concentration of adsorbed protein at the PAMAM surface was obtained at $0.6 \mu \mathrm{g} / \mathrm{mL}$, representing a densely packed protein monolayer. The almost completely irreversible adsorption regime is found only for low protein concentration characterized by formation of an NT4 monolayer at the nanoparticle surface and hence there was no observable desorption within the 4 weeks. Increasing adsorption time and protein bulk concentration caused the creation of additional protein layers at PAMAM nanoparticles (seen as a decline in residual NT4 concentration in PBS). The decline in protein molecules from the bulk solution during adsorption finally led to a steady state, which indicated slow alteration in the adlayer structure.

\section{Desorption of NT4 from PAMAM dendrimers in PBS} In order to determine the possibility of NT4 desorption from dendrimers, once adsorption reached equilibrium, we studied NT4 release in PBS. At this point, we used ELISA to evaluate more accurately concentrations of desorbed NT4 from PAMAM nanoparticles in electrolytes. The release profiles of NT4 molecules from nanoparticles at initial protein concentration of $20 \mathrm{mg} \cdot \mathrm{L}^{-1}$ is shown in Figure 4 (pH 7.4 and $0.15 \mathrm{M}$ PBS).

Initial protein concentration decreased with desorption time, reaching final steady-state values after 500 minutes (Figure 5A). Therefore, proteins were released in a biphasic mode. The first phase was characterized by a fast release of NT4 molecules, which probably resulted from the solubilization of protein that usually exists near the surface. Spontaneous electrostatic interaction led to release of $20 \%$ of NT4 in the first 2 hours, but the remaining NT4 was delivered as an irreversibly adsorbed protein at dendrimer nanoparticles. The second phase was characterized by a slow/sustained NT4-desorption profile, which could be attributed to reversible adsorption of the protein layer at polymer nanoparticles, leading to diffusion of the entrapped protein. Our results are in agreement with profiles of protein release previously presented in the literature for nanosize systems. ${ }^{62}$ Abruptly desorbing fraction of reversibly bound NT4 molecules from dendrimer nanoparticles indicates the existence of adsorbed NT aggregates or 
A

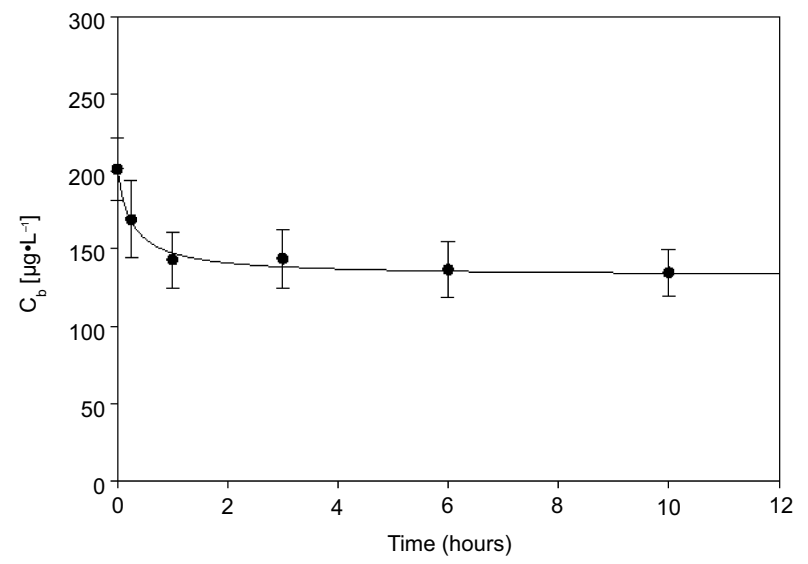

B

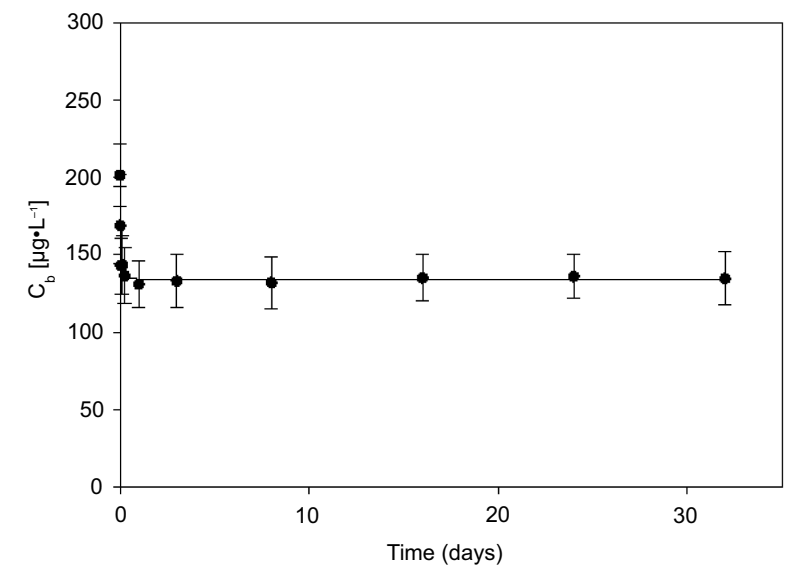

Figure 5 Desorption characteristics of NT4 from PAMAM G6 dendrimers for PBS electrolytes.

Notes: NT4 detection by ELISA over the first (A) 10 hours and (B) 32 days of incubation.

Abbreviation: PAMAM, polyamidoamine.

A

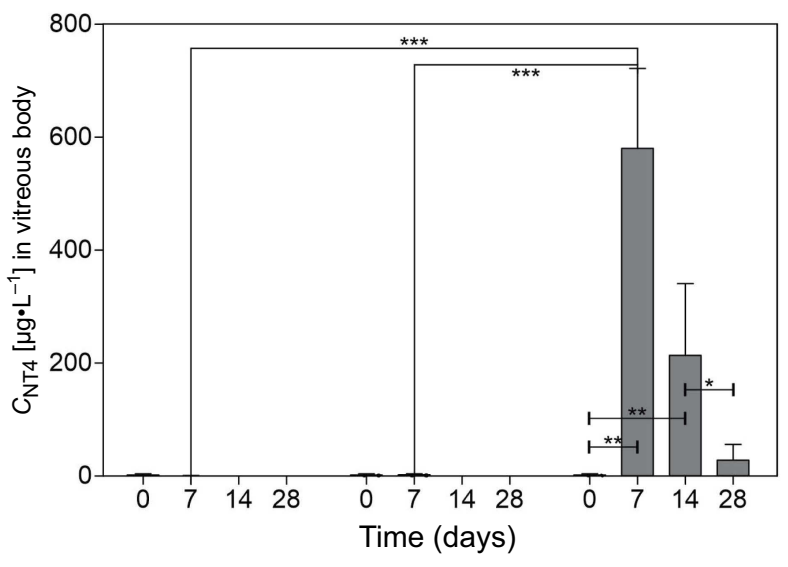

B

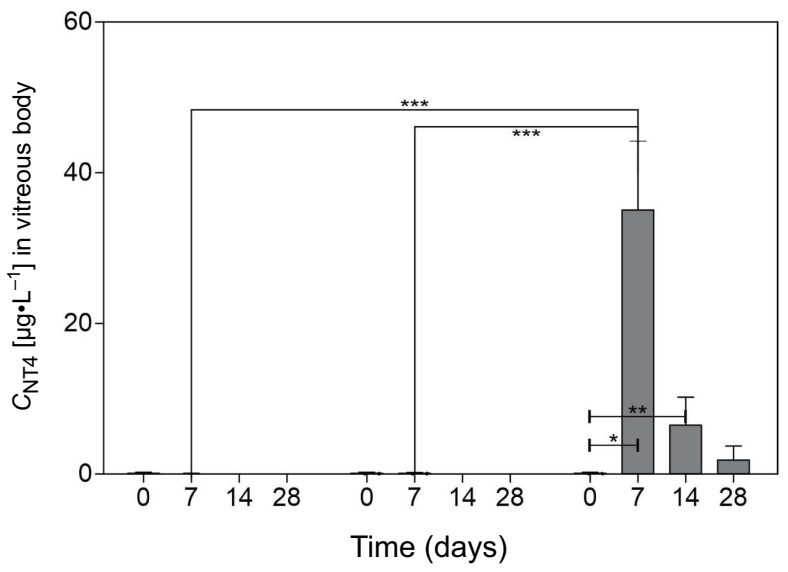

$\mathrm{NaIO}_{3}$

$\mathrm{NalO}_{3}-\mathrm{PAMAM}$

$\mathrm{NaIO}_{3}-\mathrm{NT} 4-\mathrm{PAMAM}$

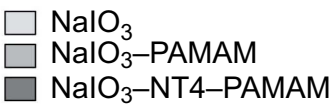

$\square \mathrm{NaIO}_{3}$

$\mathrm{NaIO}_{3}-\mathrm{NT} 4$-PAMAM

Figure 6 Desorption characteristics of NT4 proteins in vitreous body after injection of control mice (before treatment), $\mathrm{NalO}_{3}$ injection, and $\mathrm{NaIO}_{3}-\mathrm{PAMAM}$ or $\mathrm{NaIO}_{3}-$ PAMAM-NT4 injection.

Notes: (A) ELISA detection of NT4; (B) NT4 concentration normalized to total protein concentration of individual tissue samples. Results shown as means \pm SD. $* P<0.05$; $* * P<0.01 ; * * * P<0.001$.

Abbreviation: PAMAM, polyamidoamine. 
various conformations of single NT4 molecules in the adsorbed state. The binding strength of asymmetric shapes of protein aggregates could be responsible for the reversibility of the adsorption process. A fraction of NT4, which formed the next layers on the dendrimer surface, was characterized by slow desorption from the carrier over 28 days.

\section{Desorption of NT4 from PAMAM dendrimers in} vitreous bodies and injured retinas in mouse model We investigated the effect of NT4 adsorption on the in vivo transportation of PAMAM nanoparticles to the vitreous body as well as into retinal layers of mice exposed to intravenous injection of $\mathrm{NaIO}_{3}$. Systemic administration of sodium iodate is known to selectively impair the RPE, resulting in patchy loss of RPE and subsequent degeneration of photoreceptors. ${ }^{63}$ To assess the distribution of injected dendrimer-NT conjugates, we analyzed vitreous NT4 concentrations after injection of PAMAM and PAMAM-NT4 electrostatic complex with ELISA up to 28 days postinjection. Eyes exposed to retinal injury without subsequent intravitreal injection served as controls. The results are summarized in Figure 6.

Our results (Figure 6) show unequivocally that injection of a negatively charged protein-nanoparticle complex had increased NT4 concentration in vitreous bodies of injured mouse eyes by day 7 postapplication. Moreover, injected PAMAM dendrimers alone did not influence NT4 concentration at all. NT4 vitreous level decreased gradually up to 28 days after administration, being in accordance with NT4-release profiles in PBS (Figure 5). This may indicate that irreversibly adsorbed NT4 on negatively
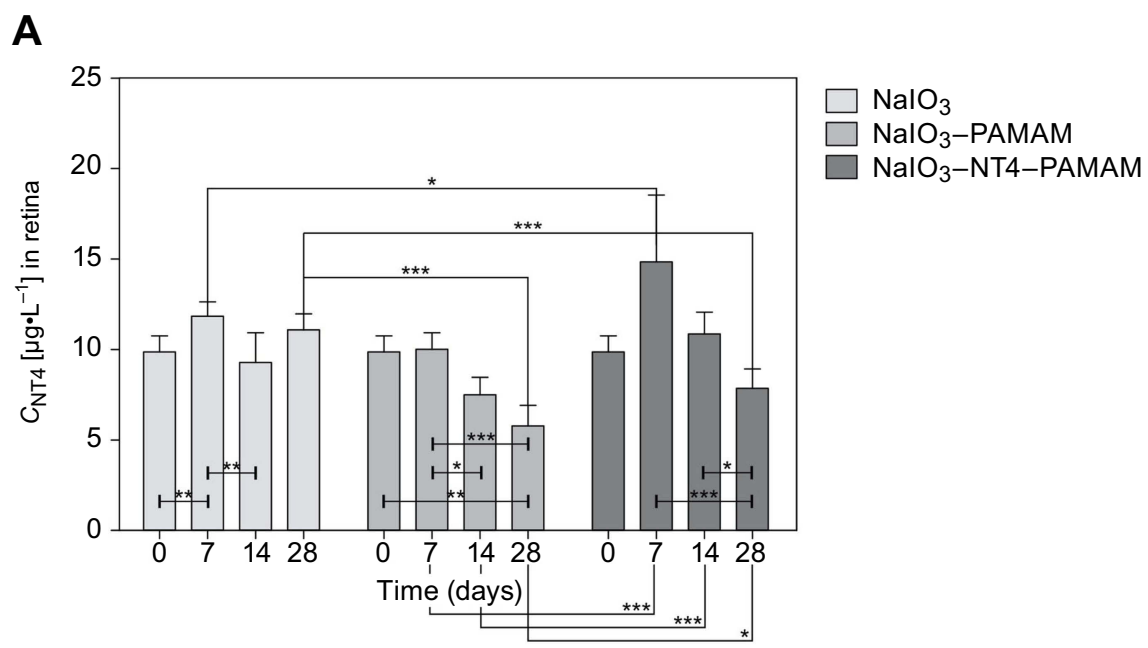

B

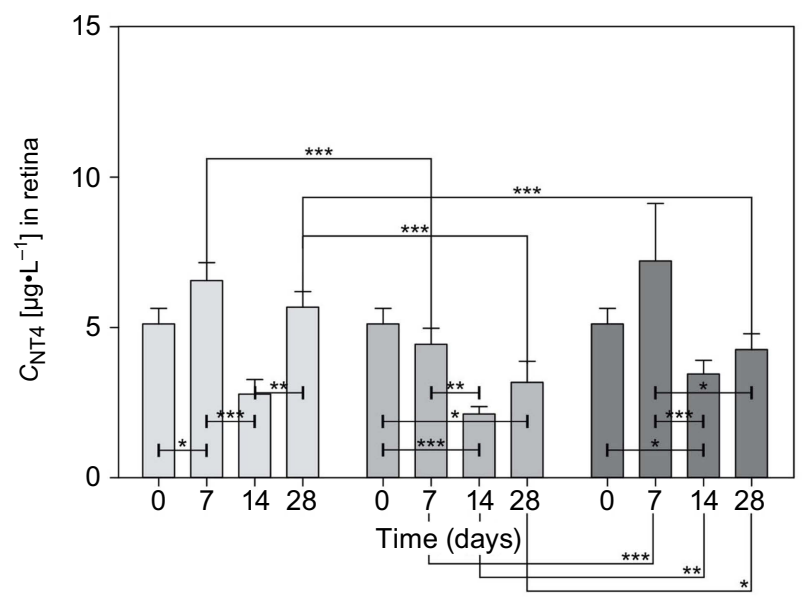

$\mathrm{NaIO}_{3}$

$\mathrm{NalO}_{3}-\mathrm{PAMAM}$

$\mathrm{NaIO}_{3}-\mathrm{NT4}-\mathrm{PAMAM}$

Figure 7 Desorption characteristics of NT4 proteins in retina after injection of control mice (before any treatment), $\mathrm{NalO}_{3}$ injection, and $\mathrm{NaIO}_{3}-\mathrm{PAMAM}$ or $\mathrm{NaIO}_{3}-$ PAMAM-NT4.

Notes: (A) ELISA detection of NT4; (B) NT4 concentration normalized to total protein concentration of individual tissue samples. Results shown as means \pm SD. $* P<0.05$; $* * P<0.01 ; * * * P<0.001$.

Abbreviation: PAMAM, polyamidoamine. 
charged dendrimers improved its tissue penetration and enabled its distribution into vitreous tissue. Furthermore, we determined desorption kinetics of NT4 from the protein-dendrimer conjugates within retinas at selected time points (days 7, 14, and 28) after intravitreal delivery (Figure 7A and B). This study was designed to quantitatively identify penetration of NT4 within damaged retinas. The results are summarized in Figure 7.

Administration of positively charged PAMAM dendrimers had increased NT4 concentration in impaired retinas compared to tissue without any carriers by day 7 postapplication. NT4 concentration decreased gradually over time. The initial concentration of NT4 in retinas without any modification on day 0 was maintained on day 28 after delivery (Figure 7). We speculate that the electrostatic or aspecific interaction of dendrimers with different types of proteins (protein corona) resulted in their removal by macrophage cells, hampering their integration with retinal layers. ${ }^{64}$ In fact, the role of the protein corona in the retina environment is vital for successful delivery of nanoparticles into retinal tissue.

Analysis of NT4 transport across mouse eyes revealed higher levels of protein concentration in the vitreous body than in damaged retina layers. The effective concentration of protein after administration of NT4-PAMAM in retinas was approximately 32 times lower than NT4 concentrations in vitreous body, which indicates that penetration of NT4 into retinal tissue was hampered. Intravitreously, distribution of NT4 was a transport- rather than elimination-limited process, as opposed to retinal tissue, where it was hampered, as illustrated in Figures 6 and 7. Penetration of the NT-dendrimer complex into retinal tissue was governed by electrostatic and hydrophobic interactions (connected with conformational transition of protein). Positively charged PAMAM nanoparticles and slightly negatively charged NT4-PAMAM complexes adsorbed onto negatively charged cell membranes. In this case, we suspect that the main force governing NT4 and NT4-PAMAM transport across the retinal tissue seen on 7 day after injection could be phagocytosis, causing NT4-PAMAM complex engulfment and sufficient removal from the bloodstream. Our results are in accordance with Ding and $\mathrm{Ma}^{64}$ Additionally, confocal analysis of mouse-eye sections (Figure 8) revealed the presence of green fluorescent particles, which may correspond to clusters of the NT4-AF488dendrimer nanoconstructs.

Particles were detected on day 7 after administration of PAMAM-NT4 complexes in vitreous bodies, but not in retinas. On day 28 after nanocomplex injection, the particles were
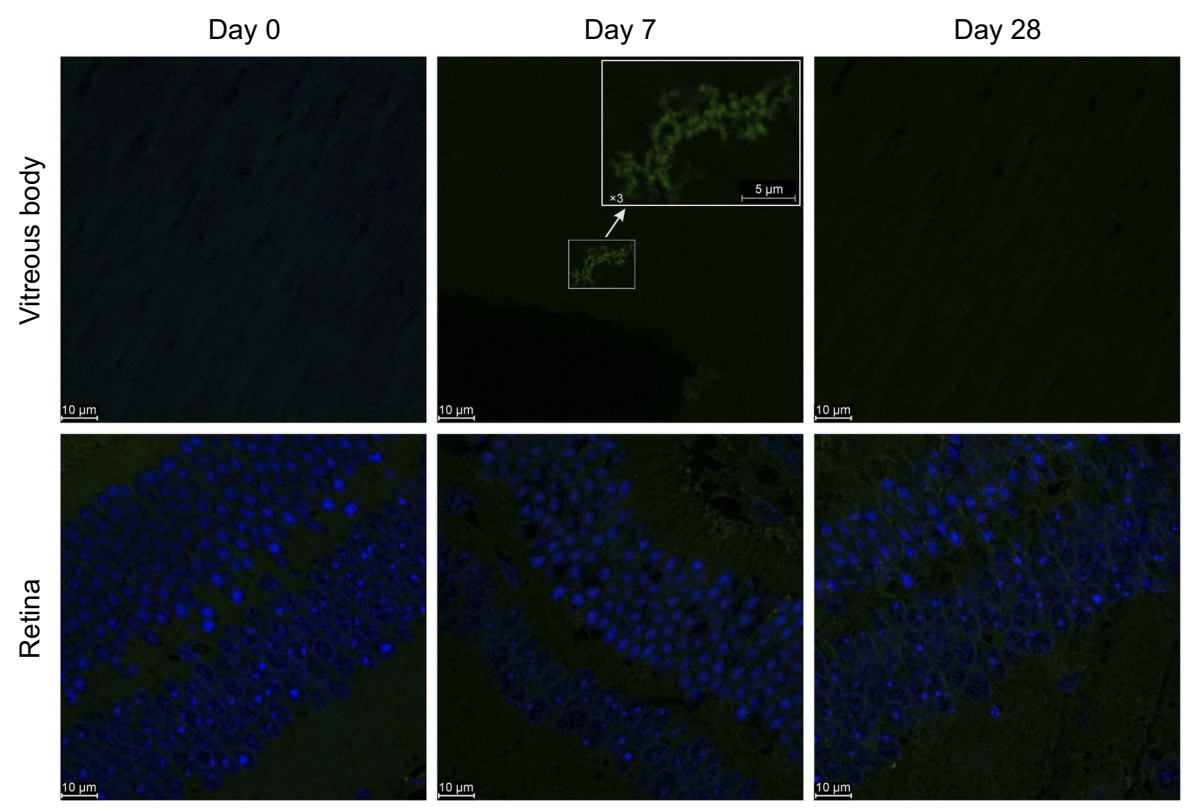

NT4-PAMAM conjugates

DAPI

Figure 8 Confocal images showing $\mathrm{NaIO}_{3}$-injured mouse eyes (vitreous body and retina) after administration of fluorescently-labeled NT4-PAMAM conjugates.

Notes: Top middle image reveals the presence of green fluorescent particles that may correspondto nanocomplexes in the vitreous body only 7 days after NT4-PAMAM injection. Particles were undetectable in the retina at all study time points (bottom row). Magnification 63×, oil immersion. Blue fluorescence, nuclei (DAPI); green background, tissue autofluorescence.

Abbreviation: PAMAM, polyamidoamine. 
already undetectable in eyeballs, vitreous bodies, and retinas. Microscopywas consistent with the data obtained from ELISA, confirming the highest concentration of therapeutic complexes in vitreous bodies within 7 days of administration.

\section{Conclusion}

Our goal in this study was to quantitatively identify a transition from reversible to irreversible adsorption of NT4 to design a protein-dendrimer electrostatic complex for NT delivery to impaired retinal tissue. From our in situ measurements, we conclude that adsorption/desorption of NT4 from PAMAM nanoparticles in the PBS environment for the range of $\mathrm{pH}$ close to and below the isoelectric point is dependent on electrostatic interactions. We have pointed out that increasing adsorption time and protein bulk concentration caused the creation of additional protein layers at PAMAM nanoparticles (seen as a decline in residual NT4 concentration in PBS).

Our results obtained from desorption study in PBS by concentration-depletion methods are in agreement with data collected from the NT4-release profile in vitreous bodies. On the other hand, when the NT4-PAMAM conjugate interacted with cells in retinal tissue, we observed lower cellular uptake, indicating that tissue penetration of NT4 was an eliminationrather than transport- limited process. We established that efficacy of NT4-PAMAM electrostatic conjugate delivery across retinal tissue is likely dependent on electrostatic or aspecific interaction with the negatively charged cell membrane. Therefore, it may be concluded that understanding the adsorption-desorption transition of NTs to/from nanoparticles is essential for rational design of an NT-delivery system, which could overcome restricted retinal tissue penetration.

\section{Acknowledgments}

This work was supported by the National Centre for Research and Development, grant STRATEGMED1/234261/2NCBR/ 2014. We wish to thank Professor Mirosława El Fray from the Polymer Institute, West Pomeranian University of Technology, for allowing us to use the equipment. We would also like to thank Professor Barbara Wiszniewska from the Department of Histology and Embryology, Pomeranian Medical University, for helping us with histological preparation.

\section{Disclosure}

The authors report no conflicts of interest in this work.

\section{References}

1. Molina-Holgado F, Doherty P, Williams G. Tandem repeat peptide strategy for the design of neurotrophic factor mimetics. CNS Neurol Disord Drug Targets. 2008;7(1):110-119. doi:10.2174/ 187152708783885200

2. Scott-Solomon E, Kuruvilla R. Mechanisms of neurotrophin trafficking via Trk receptors. Mol Cell Neurosci. 2018;91:25-33. doi:10.1016/j. men.2018.03.013

3. Machalinska A, Kawa M, Pius-Sadowska E, et al. Long-term neuroprotective effects of NT-4-engineered mesenchymal stem cells injected intravitreally in a mouse model of acute retinal injury. Invest Ophthalmol Vis Sci. 2013;54(13):8292-8305. doi:10.1167/ iovs.13-12221

4. BDNF study group (phase III). A controlled trial of recombinant methionyl human BDNF in ALS.Neurology. 1999;52(7):1427-1433. doi:10.1212/WNL.52.7.1427

5. Geral C, Angelova A, Lesieur S. From molecular to nanotechnology strategies for delivery of neurotrophins: emphasis on brain-derived neurotrophic factor (BDNF). Pharmaceutics. 2013;5(1):127-167. doi:10.3390/pharmaceutics5010127

6. Park H, Poo MM. Neurotrophin regulation of neural circuit development and function. Nat Rev Neurosci. 2013;14(1):7-23. doi:10.1038/ nrn3379

7. Weissmiller AM, Wu C. Current advances in using neurotrophic factors to treat neurodegenerative disorders. Transl Neurodegener. 2012;1(1):14. doi:10.1186/2047-9158-1-14

8. Allen SJ, Watson JJ, Shoemark DK, Barua NU, Patel NK. GDNF, NGF and BDNF as therapeutic options for neurodegeneration. Pharmacol Ther. 2013;138(2):155-175. doi:10.1016/j. pharmthera.2013.01.004

9. Iezzi R, Guru BR, Glybina IV, Mishra MK, Kennedy A, Kannan RM. Dendrimer-based targeted intravitreal therapy for sustained attenuation of neuroinflammation in retinal degeneration. Biomaterials. 2012;33(3):979-988. doi:10.1016/j.biomaterials.2011.10.010

10. LaVail MM, Unoki K, Yasumura D, Matthes MT, Yancopoulos GD, Steinberg RH. Multiple growth factors, cytokines, and neurotrophins rescue photoreceptors from the damaging effects of constant light. Proc Natl Acad Sci U S A. 1992;89(23):11249-11253. doi:10.1073/ pnas.89.23.11249

11. Paskowitz DM, Donohue-Rolfe KM, Yang H, et al. Neurotrophic factors minimize the retinal toxicity of verteporfin photodynamic therapy. Invest Ophthalmol Vis Sci. 2007;48(1):430-437. doi:10.1167/iovs.06-0690

12. Birch DG, Weleber RG, Duncan JL, Jaffe GJ, Tao W. Randomized trial of ciliary neurotrophic factor delivered by encapsulated cell intraocular implants for retinitis pigmentosa. Am J Ophthalmol. 2013;156(2):283-292.e1. doi:10.1016/j.ajo.2013.03.021

13. El Sanharawi M, Kowalczuk L, Touchard E, Omri S, de Kozak Y, Behar-Cohen F. Protein delivery for retinal diseases: from basic considerations to clinical applications. Prog Retin Eye Res. 2010;29 (6):443-465. doi:10.1016/j.preteyeres.2010.04.001

14. Sahoo SK, Dilnawaz F, Krishnakumar S. Nanotechnology in ocular drug delivery. Drug Discov Today. 2008;13(3-4):144-151. doi:10.1016/j.drudis.2007.10.021

15. Achouri D, Alhanout K, Piccerelle P, Andrieu V. Recent advances in ocular drug delivery. Drug Dev Ind Pharm. 2013;39(11):1599-1617. doi: $10.3109 / 03639045.2012 .736515$

16. McNerny DQ, Leroueil PR, Baker JR. Understanding specific and nonspecific toxicities: a requirement for the development of dendrimer-based pharmaceuticals. Wiley Interdiscip Rev Nanomed Nanobiotechnol. 2010;2(3):249-259. doi:10.1002/wnan.79

17. Quintana A, Raczka E, Piehler L, et al. Design and function of a dendrimer-based therapeutic nanodevice targeted to tumor cells through the folate receptor. Pharm Res. 2002;19(9):1310-1316. 
18. Thomas TP, Majoros IJ, Kotlyar A, et al. Targeting and inhibition of cell growth by an engineered dendritic nanodevice. J Med Chem. 2005;48(11):3729-3735. doi:10.1021/jm040187v

19. Mignani S, El Kazzouli S, Bousmina M, Majoral JP. Expand classical drug administration ways by emerging routes using dendrimer drug delivery systems: a concise overview. Adv Drug Deliv Rev. 2013;65 (10):1316-1330. doi:10.1016/j.addr.2013.01.001

20. Leroueil PR, Berry SA, Duthie K, et al. Wide varieties of cationic nanoparticles induce defects in supported lipid bilayers. Nano Lett. 2008;8(2):420-424. doi:10.1021/n10722929

21. Malik N, Wiwattanapatapee R, Klopsch R, et al. Dendrimers: relationship between structure and biocompatibility in vitro, and preliminary studies on the biodistribution of 125I-labelled polyamidoamine dendrimers in vivo. J Control Release. 2000;65(1-2):133-148.

22. Jevprasesphant R, Penny J, Jalal R, Attwood D, McKeown NB, D'Emanuele A. The influence of surface modification on the cytotoxicity of PAMAM dendrimers. Int J Pharm. 2003;252(1-2):263-266.

23. Roberts JC, Bhalgat MK, Zera RT. Preliminary biological evaluation of polyamidoamine (PAMAM) Starburst dendrimers. J Biomed Mater Res. 1996;30(1):53-65. doi:10.1002/(SICI)1097-4636(199601) 30:1<53::AID-JBM8>3.0.CO;2-Q

24. Das AK, Hsiao PY. Charged dendrimers in trivalent salt solutions under the action of DC electric fields. J Phys Chem B. 2014;118 (23):6265-6276. doi:10.1021/jp4116589

25. Tokarczyk K, Jachimska B. Quantitative interpretation of PAMAM dendrimers adsorption on silica surface. J Colloid Interface Sci. 2017;503:86-94. doi:10.1016/j.jcis.2017.05.002

26. Jachimska B, Lapczynska M, Zapotoczny S. Reversible swelling process of sixth-generation Poly(amido amine) dendrimers molecule as determined by quartz crystal microbalance technique. J Phys Chem C. 2013;117(2):1136-1145. doi:10.1021/jp307832p

27. Porus M, Clerc F, Maroni P, Borkovec M. Ion-specific responsiveness of polyamidoamine (PAMAM) dendrimers adsorbed on silica substrates. Macromolecules. 2012;45(9):3919-3927. doi:10.1021/ ma3004295

28. Welch P, Muthukumar M. Tuning the density profile of dendritic polyelectrolytes. Macromolecules. 1998;31(17):5892-5897. doi:10.1021/ ma980198w

29. Li N, Cai H, Jiang L, et al. Enzyme-Sensitive and amphiphilic PEGylated dendrimer-paclitaxel prodrug-based nanoparticles for enhanced stability and anticancer efficacy. ACS Appl Mater Interfaces. 2017;9(8):6865-6877. doi:10.1021/acsami.6b15505

30. Lamy CM, Sallin O, Loussert C, Chatton JY. Sodium sensing in neurons with a dendrimer-based nanoprobe. ACS Nano. 2012;6 (2):1176-1187. doi:10.1021/nn203822t

31. Choi SK, Myc A, Silpe JE, et al. Dendrimer-based multivalent vancomycin nanoplatform for targeting the drug-resistant bacterial surface. ACS Nano. 2013;7(1):214-228. doi:10.1021/nn3038995

32. Wang F, Zhang B, Zhou L, et al. Imaging dendrimer-grafted graphene oxide mediated anti-miR-21 delivery with an activatable luciferase reporter. ACS Appl Mater Interfaces. 2016;8(14):9014-9021. doi:10.1021/acsami.6b02662

33. Cao J, Ge R, Zhang M, et al. A triple modality BSA-coated dendritic nanoplatform for NIR imaging, enhanced tumor penetration and anticancer therapy. Nanoscale. 2018;10(19):9021-9037. doi:10.1039/ c7nr09552j

34. Kim K, Lee J, Jo G, Shin S, Kim JB, Jang JH. Dendrimer-capped gold nanoparticles for highly reliable and robust surface enhanced Raman scattering. ACS Appl Mater Interfaces. 2016;8(31):2037920384. doi:10.1021/acsami.6b05710

35. Ma W, Fu F, Zhu J, et al. 64Cu-Labeled multifunctional dendrimers for targeted tumor PET imaging. Nanoscale. 2018;10(13):6113-6124. doi:10.1039/c7nr09269e

36. Giri J, Diallo MS, Simpson AJ, et al. Interactions of poly(amidoamine) dendrimers with human serum albumin: binding constants and mechanisms. ACS Nano. 2011;5(5):3456-3468. doi:10.1021/nn1021007
37. Curtis RA, Ulrich J, Montaser A, Prausnitz JM, Blanch HW. Proteinprotein interactions in concentrated electrolyte solutions. Biotechnol Bioeng. 2002;79(4):367-380. doi:10.1002/bit.10342

38. Lin YL, Khanafer K, El-Sayed ME. Quantitative evaluation of the effect of poly(amidoamine) dendrimers on the porosity of epithelial monolayers. Nanoscale. 2010;2(5):755-762. doi:10.1039/b9nr00407f

39. Yang $\mathrm{B}, \mathrm{Xu} \mathrm{H}$, Wang $\mathrm{S}$, et al. Studying the dynamic mechanism of transporting a single drug carrier-polyamidoamine dendrimer through cell membranes by force tracing. Nanoscale. 2016;8(42):1802718031. doi:10.1039/c6nr05838h

40. Dabkowska M, Adamczyk Z, Cie?la M, Adamczak M, Bober J. Lysozyme monolayers at polymer microparticles: electrokinetic characteristics and modeling. J Phys Chem C. 2018;122(31):1784617855. doi:10.1021/acs.jpcc.8b04916

41. Kujda M, Adamczyk Z, Ciesla M. Monolayers of the HSA dimer on polymeric microparticles-electrokinetic characteristics. Colloids Surf B Biointerfaces. 2016;148:229-237. doi:10.1016/j.colsurfb.2016.08.017

42. Bratek-Skicki A, Zeliszewska P, Adamczyk Z, Ciesla M. Human fibrinogen monolayers on latex particles: role of ionic strength. Langmuir. 2013;29(11):3700-3710. doi:10.1021/1a400419y

43. Zhenhua XT, Yiyun Cheng X, Minglu M, Peng X, Haiou Q, Wen L. Colorimetric determination of polyamidoamine dendrimers and their derivates using a simple and rapid ninhydrin assay. Anal Lett. 2008;41:444-455. doi:10.1080/00032710701484350

44. Adamczyk Z, Bratek-Skicki A, Dabrowska P, Nattich-Rak M. Mechanisms of fibrinogen adsorption on latex particles determined by zeta potential and AFM measurements. Langmuir. 2012;28 (1):474-485. doi:10.1021/la2038119

45. Machalinska A, Kawa MP, Pius-Sadowska E, et al. Endogenous regeneration of damaged retinal pigment epithelium following low dose sodium iodate administration: an insight into the role of glial cells in retinal repair. Exp Eye Res. 2013;112:68-78. doi:10.1016/j. exer.2013.04.004

46. Machalinska A, Roginska D, Pius-Sadowska E, et al. Neuroprotective and antiapoptotic activity of lineage-negative bone marrow cells after intravitreal injection in a mouse model of acute retinal injury. Stem Cells Int. 2015;2015:620364. doi:10.1155/2015/620364

47. Dabkowska M, Adamczak M, Barbasz J, Ciesla M, Machalinski B. Adsorption/desorption transition of recombinant human neurotrophin 4: physicochemical characterization. Langmuir. 2017;33(38):95489557. doi:10.1021/acs.langmuir.7b00909

48. Mullen DG, Fang M, Desai A, Baker JR, Orr BG, Banaszak Holl MM. A quantitative assessment of nanoparticle-ligand distributions: implications for targeted drug and imaging delivery in dendrimer conjugates. ACS Nano. 2010;4(2):657-670. doi:10.1021/ nn900999c

49. Wasilewska M, Adamczyk Z, Jachimska B. Structure of fibrinogen in electrolyte solutions derived from dynamic light scattering (DLS) and viscosity measurements. Langmuir. 2009;25(6):3698-3704. doi: $10.1021 / 1 \mathrm{a} 803662 \mathrm{a}$

50. Adamczyk Z, Bratek A, Jachimska B, Jasinski T, Warszynski P. Structure of poly(acrylic acid) in electrolyte solutions determined from simulations and viscosity measurements. J Phys Chem B. 2006;110(45):22426-22435. doi:10.1021/jp063981w

51. Delgado AV, Gonzalez-Caballero F, Hunter RJ, Koopal LK, Lyklema J. Measurement and interpretation of electrokinetic phenomena. J Colloid Interface Sci. 2007;309(2):194-224. doi:10.1016/j.jcis.2006.12.075

52. Roberts D, Keeling R, Tracka M, et al. Specific ion and buffer effects on protein-protein interactions of a monoclonal antibody. Mol Pharm. 2015;12(1):179-193. doi:10.1021/mp500533c

53. Adamczyk Z, Nattich M, Wasilewska M, Zaucha M. Colloid particle and protein deposition - electrokinetic studies. Adv Colloid Interface Sci. 2011;168(1-2):3-28. doi:10.1016/j.cis.2011.04.002

54. Aubin-Tam ME, Hamad-Schifferli K. Structure and function of nanoparticle-protein conjugates. Biomed Mater. 2008;3(3):034001. doi:10.1088/1748-6041/3/3/034001 
55. Geoghegan WD, Ackerman GA. Adsorption of horseradish peroxidase, ovomucoid and anti-immunoglobulin to colloidal gold for the indirect detection of concanavalin $\mathrm{A}$, wheat germ agglutinin and goat anti-human immunoglobulin $\mathrm{G}$ on cell surfaces at the electron microscopic level: a new method, theory and application. J Histochem Cytochem. 1977;25(11):1187-1200. doi:10.1177/25.11.21217

56. Bayraktar H, You CC, Rotello VM, Knapp MJ. Facial control of nanoparticle binding to cytochrome C. J Am Chem Soc. 2007;129 (10):2732-2733. doi:10.1021/ja067497i

57. Adamczyk Z. Particles at Interfaces. Vol. 20. Amsterdam: Elsevier; 2017:700.

58. Serra J, Puig J, Martin A, Galisteo F, Galvez J, Hildago-Alvarez R. On the adsorption of IgG onto polystyrene particles: electrophoretic mobility and critical coagulation concentration. Colloid Polym Sci. 1992;270(6):574-583. doi:10.1007/BF00658288

59. Bharti B, Meissner J, Findenegg GH. Aggregation of silica nanoparticles directed by adsorption of lysozyme. Langmuir. 2011;27 (16):9823-9833. doi:10.1021/la201898v
60. Meder F, Daberkow T, Treccani L, et al. Protein adsorption on colloidal alumina particles functionalized with amino, carboxyl, sulfonate and phosphate groups. Acta Biomater. 2012;8(3):1221-1229. doi:10.1016/j.actbio.2011.09.014

61. Klose T, Welzel PB, Werner C. Protein adsorption from flowing solutions on pure and maleic acid copolymer modified glass particles. Colloids Surf B Biointerfaces. 2006;51(1):1-9. doi:10.1016/j.colsurfb.2006.04.019

62. Elliott Donaghue I, Tator $\mathrm{CH}$, Shoichet MS. Sustained delivery of bioactive neurotrophin-3 to the injured spinal cord. Biomater Sci. 2015;3(1):65-72. doi:10.1039/c4bm00311j

63. Machalinska A, Lubinski W, Klos P, et al. Sodium iodate selectively injuries the posterior pole of the retina in a dose-dependent manner: morphological and electrophysiological study. Neurochem Res. 2010;35(11):1819-1827. doi:10.1007/s11064010-0248-6

64. Ding HM, Ma YQ. Computer simulation of the role of protein corona in cellular delivery of nanoparticles. Biomaterials. 2014;35 (30):8703-8710. doi:10.1016/j.biomaterials.2014.06.033
International Journal of Nanomedicine

\section{Publish your work in this journal}

The International Journal of Nanomedicine is an international, peerreviewed journal focusing on the application of nanotechnology in diagnostics, therapeutics, and drug delivery systems throughout the biomedical field. This journal is indexed on PubMed Central, MedLine, CAS, SciSearch ${ }^{\mathbb{B}}$, Current Contents ${ }^{\mathbb{B}} /$ Clinical Medicine,

\section{Dovepress}

Journal Citation Reports/Science Edition, EMBase, Scopus and the Elsevier Bibliographic databases. The manuscript management system is completely online and includes a very quick and fair peer-review system, which is all easy to use. Visit http://www.dovepress.com/ testimonials.php to read real quotes from published authors. 